\title{
Student chapter formed
}

As many have already noticed, the Education Committee of the MRS has begun a renewed effort to encourage the formation of Student Chapters of the Society located on university campuses where significant research and education in materials science is ongoing. Rodney C. Ewing (the newly elected Secretary of the MRS) has been spearheading this effort. One such Student Chapter, in existence for some time, is located at the University of California at Los Angeles. At the University of Pennsylvania in Philadelphia, a group of students had already formed the nucleus of a materials research oriented chapter before the recent MRS campaign began. On receiving the Education Committee's inquiry, the students' adviser, Professor John E. Fischer, immediately notified the Society of the interest on their campus. Professor Fischer is a member of the faculty of the Department of Materials Science and Engineering and is also Assistant Director of the Laboratory for Research on the Structure of Matter (LRSM). The LRSM at the University of Pennsylvania is one the Materials Research Laboratories in the National Science Foundation's MRL program and, in fact, was one of the first such laboratories some 24 years ago.

\section{The Society's Swift Response}

The Society's response to this expression of interest was swift indeed. Within one month, First Vice President and President Elect Elton N. Kaufmann arrived on campus to officially inaugurate the new chapter. On Oct. 18, after delivering a seminar on his current research, Kaufmann presented the new chapter's charter to the student executive committee during a ceremony in the auditorium of the LRSM.

The student members of the executive committee reflect the interdisciplinarity of the group. They are Tom Fare (Electrical Engineering), Rich Demmin (Chemical Engineering), Vicki Cajipe (Physics), Steve Yalisove (Materials Science and Engineering), and Marie Angelopoulos (Chemistry).

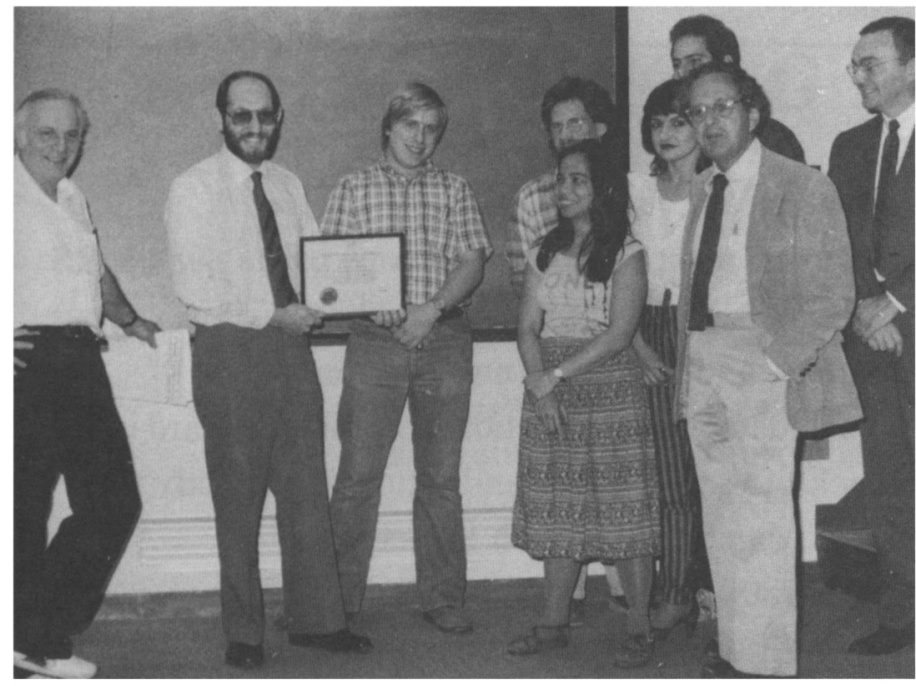

Presentation Ceremony (from left to right): DAVID WHITE, Director of LRSM, ELTON KAUFMANN, RICH DEMMIN, TOM FARE (back), VICKI CAJIPE, MARIE ANGELOPOULOS, STEVE YALISOVE (back), RALPH AMADO, Chairman of the Physics Department, and JOSEPH BORDOGNA, Dean of Engineering. The Certificate of Charter grants the Student Chapter with "all the rights, privileges, and responsibilities of the Society .... in promoting an interdisciplinary approach to the science and technology of materials."

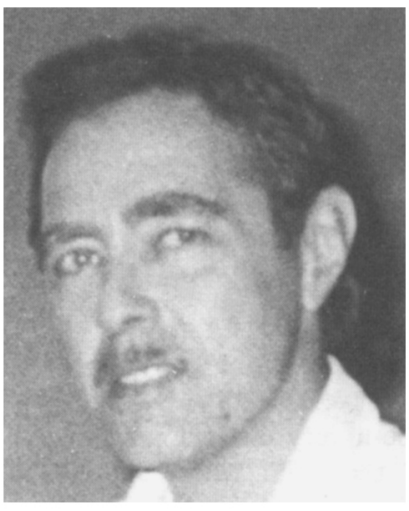

JOHN FISCHER

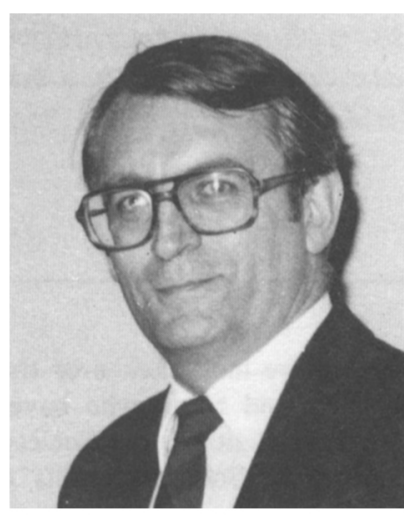

ANDREW MCGHIE
The ceremony was followed by a social hour attended by all interested students and several University officials. During the reception, Kaufmann was presented with a poem in honor of the occasion. It was authored and read by Dr. Andrew R. McGhie, a Scotsman and organic chemist on the University staff. It is reprinted below:

We are gathered here this afternoon
For an inauguration,
And symbolically it is only
The second in the nation.
We celebrate the fledgling birth
Of a new society,
As materials research will rule the earth
For a decade or two or three.
Yes they are so important
For on them all things depend,
From the concepts in the beginning
To the products at the end.
Thus leaders with great foresight,
They thought it very prudent
To institute a chapter
Composed of superior students.
And so to Pennsylvania
Today the honor lies,
As the president of the society
From Livermore here he hies.
And to Dr. Elton Kaufmann
We extend to him our thanks,
For coming here this afternoon
To induct us into the ranks
Of the Materials Research Society
As its second student chapter,
And hope that soon so many more
Will follow us hereafter.

Kaufmann reports that "the students at the University of Pennsylvania displayed a high level of enthusiasm for their studies in materials and indicated that the MRS is a vehicle they hope will help them achieve a greater involvement in the materials community while their chapter provides an additional opportunity for scientific interchanges on the campus." He said, "I very much appreciated the chance to visit and take part in the chapter inauguration and was pleasantly surprised when presented with a poem which prematurely promoted me to president and was quite appropriate and well composed, particularly when one realizes that Dr. McGhie was given less than two hours to accomplish the task." 